\title{
A Mobile App for the Self-Management of Type 1 Diabetes Among Adolescents: A Randomized Controlled Trial
}

Shivani Goyal ${ }^{1,2^{*}}$, BEng, MSc, PhD; Caitlin A Nunn ${ }^{3 *}$, MSc; Michael Rotondi ${ }^{4}, \mathrm{PhD}$; Amy B Couperthwaite ${ }^{4}$, MSc; Sally Reiser ${ }^{5}$, RD; Angelo Simone ${ }^{5}, \mathrm{MD}$; Debra K Katzman ${ }^{6,7}, \mathrm{MD}, \mathrm{FRCP}(\mathrm{C})$; Joseph A Cafazzo ${ }^{1,2,8}$, PhD, PEng; Mark R Palmert ${ }^{3,6,9}, \mathrm{MD}, \mathrm{PhD}$

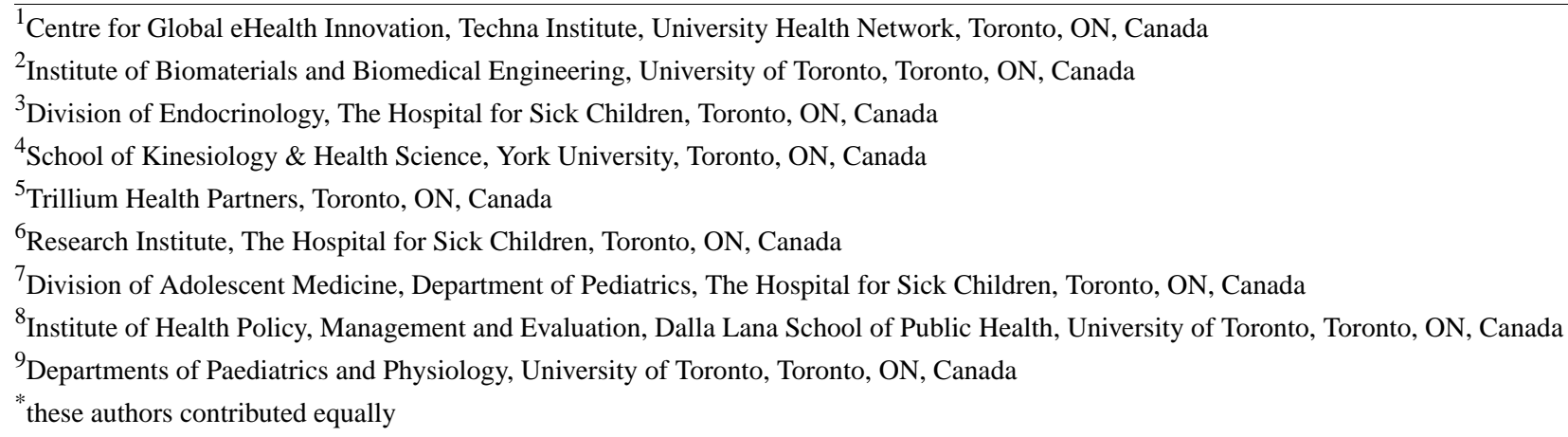

\section{Corresponding Author:}

Shivani Goyal, BEng, MSc, PhD

Centre for Global eHealth Innovation

Techna Institute

University Health Network

190 Elizabeth Street

Toronto, ON, M5G 2C4

Canada

Phone: 14163404800 ext 4765

Fax: 14163403595

Email: Shivani.goyal@uhn.ca

\section{Abstract}

Background: While optimal blood glucose control is known to reduce the long-term complications associated with type 1 diabetes mellitus, adolescents often struggle to achieve their blood glucose targets. However, their strong propensity toward technology presents a unique opportunity for the delivery of novel self-management interventions. To support type 1 diabetes self-management in this population, we developed the diabetes self-management app bant, which included wireless blood glucose reading transfer, out-of-range blood glucose trend alerts, coaching around out-of-range trend causes and fixes, and a point-based incentive system.

Objective: The primary objective was to evaluate bant 's effect on hemoglobin $\mathrm{A}_{1 \mathrm{c}}\left(\mathrm{Hb}_{1 \mathrm{c}}\right)$ through a randomized controlled trial (RCT). Secondary measures (eg, self-monitoring of blood glucose [SMBG]) were also collected to assess bant's impact on the self-management behaviors of adolescents with type 1 diabetes.

Methods: We enrolled 92 adolescents into a 12-month RCT, with 46 receiving usual care and 46 receiving usual care plus bant. Clinical outcome data were collected at quarterly research visits via validated tools, electronic chart review, glucometer downloads, and semistructured interviews. App satisfaction was assessed at 6 and 12 months, and at trial end, users ranked bant components based on perceived usefulness. Mobile analytics captured frequency of blood glucose uploads, which were used to categorize participants into high, moderate, low, or very low engagement levels.

Results: Linear mixed models showed no changes in primary and secondary clinical outcomes. However, exploratory regression analysis demonstrated a statistically significant association between increased SMBG and improved $\mathrm{HbA}_{1 \mathrm{c}}$ in the intervention group. For a subgroup of bant users taking SMBG $\geq 5$ daily, there was a significant improvement in $\mathrm{HbA}_{1 \mathrm{c}}$ of $0.58 \%(P=.02)$, while the parallel subgroup in the control arm experienced no significant change in $\mathrm{HbA}_{1 \mathrm{c}}($ decrease of $0.06 \%, P=.84)$. Although 
app usage did diminish over the trial, on average, 35\% (16/46 participants) were classified as moderately or highly engaged (uploaded SMBG $\geq 3$ days a week) over the 12 months.

Conclusion: Although primary analysis of clinical outcomes did not demonstrate differences between the bant and control groups, exploratory analysis suggested that bant may positively impact the use of SMBG data and glycemic control among youth. The next generation of bant will aim to remove barriers to use, such as deploying the app directly to personal devices instead of secondary research phones, and to explore the utility of integrating bant into routine clinical care to facilitate more frequent feedback. Future evaluations of mHealth apps should consider more robust research tools (eg, ResearchKit) and alternative RCT study designs to enable more rapid and iterative evaluations, better suited to the nature of rapidly evolving consumer technology.

Trial Registration: ClinicalTrials.gov NCT01899274; https://clinicaltrials.gov/ct2/show/NCT01899274 (Archived by WebCite at http://www.webcitation.org/6qWrqF1yw)

(JMIR Mhealth Uhealth 2017;5(6):e82) doi: 10.2196/mhealth.7336

\section{KEYWORDS}

diabetes mellitus; mobile phone; cell phones; mobile applications; behavior change; blood glucose; self-management; self-care; adolescent; gamification

\section{Introduction}

Type 1 diabetes mellitus is among the most common chronic diseases affecting children, adolescents, and adults, with an increasing worldwide incidence of approximately $3 \%$ to $4 \%$ a year [1,2]. Optimizing blood glucose control is important for patients with type 1 diabetes, as improved control has been shown to reduce the incidence and severity of type 1 diabetes complications and diabetes-related mortality [3-6]. However, achieving optimal control requires intensive self-management, which can be challenging for patients to achieve. Adolescents, in particular, struggle with optimizing blood glucose control, with worldwide data indicating they consistently fail to meet their prescribed therapeutic targets [7,8].

Overall, advancements in the mechanism of insulin delivery (ie, insulin pump or multiple daily injections) has had a limited impact on glycemic control among youth $[9,10]$. Instead, research has suggested that self-care factors, such as targeted goal setting and improved self-monitoring of blood glucose (SMBG), along with educational models, may have a greater impact on health outcomes [11-13]. Given adolescents' propensity for new technology, eHealth interventions may provide a unique opportunity to communicate with and motivate youth and thereby improve their diabetes management [14,15]. Teenagers are adopting new forms of technology quicker and in a more immersive way than any other age group, with the mobile phone becoming a primary communication tool for this demographic [16,17]. In 2015, it was reported that $88 \%$ of American teens either owned or had access to a mobile phone, up from $45 \%$ in 2004 [16,17].

Recently, the use of mHealth apps as a tool for improved diabetes self-management has proliferated, as illustrated by the number of diabetes apps available for download on the iOS App Store and Google Play [18-23]. While interest in this technology continues to rise, the clinical utility of these apps remains unclear [24]. Only a limited number of diabetes apps have completed rigorous evaluation and, to date, most studies have been conducted for the adult [25] and/or type 2 diabetes mellitus population [26,27]. How effective these apps are among adolescents with type 1 diabetes remains unknown.
Furthermore, many of the existing apps require manual entry of blood glucose values and focus primarily on the display of diabetes-related data, such as blood glucose readings, carbohydrate intake, and insulin doses [24,28]. However, recent reviews have demonstrated that very few of these apps use this information to provide users with personalized feedback, education, or motivation [28-30]. With clinical guidelines emphasizing the importance of individualized feedback and targeted education, failing to provide users with these features puts current apps at risk of simply mirroring paper-based tools, instead of being a means for behavior change and comprehensive self-management [31].

Therefore, the objective of this research was to design, develop, and evaluate bant, an app aimed to assist adolescents with the self-management of type 1 diabetes. In 2010-2011, a pilot version of bant was developed and evaluated through a 12-week pilot study $(n=20)$ among adolescents with type 1 diabetes, aged 12-16 years, with hemoglobin $\mathrm{A}_{1 \mathrm{c}}\left(\mathrm{HbA}_{1 \mathrm{c}}\right)$ between $8 \%$ and $10 \%$. Results showed an increase in daily SMBG by $50 \%$ $(P=.006)$ and a high reported level of satisfaction, with $88 \%$ of respondents stating they would continue to use the system [32]. While use of bant led to improved self-management behaviors, the trial was not designed to assess effect on $\mathrm{HbA}_{1 \mathrm{c}}$. This paper reports the results of a 12-month randomized controlled trial (RCT) conducted to assess the effectiveness of an updated version of bant as a self-management tool for adolescents with type 1 diabetes (ClinicalTrials.gov NCT01899274; Multimedia Appendix 1 [33]).

\section{Methods}

Adolescents with a diagnosis of type 1 diabetes, between the ages of 11 and 16 years, were randomly assigned to 1 of 2 groups: (1) the bant (intervention) group, or (2) the treatment as usual (control) group. Both groups were followed for a duration of 12 months.

\section{Ethical Approval}

Before initiating the study, protocol approval was obtained from all site-specific ethical review boards and/or committees (The 
Hospital for Sick Children: \#1000036524; University Health Network: \#13-6237-BE; Trillium Health Partners: \#619).

\section{Enrollment}

We recruited participants from August 2013 to December 2014 from 2 pediatric endocrinology centers in Toronto, Ontario, Canada. The final study visit was completed in January 2016. Patients were eligible to participate if they (1) had a diagnosis of type 1 diabetes mellitus (as defined by Canadian Diabetes Association guidelines [31]) for 1 year or more, (2) were between the ages of 11 and 16 years, inclusive, at the time of enrollment, (3) had been followed at the current clinic for at least 6 months, and (4) had 2 of their 3 most recent $\mathrm{HbA}_{1 \mathrm{c}}$ readings (including the day of enrollment) between $8.0 \%$ and $10.5 \%$. We selected this $\mathrm{HbA}_{1 \mathrm{c}}$ range in an attempt to identify patients who were struggling with their glycemic control, and for whom the use of a smartphone app alone might be an appropriate intervention. Given that bant was only offered in English at the time of recruitment, participants were excluded if they did not fluently speak and understand English. All participants and parents provided written, informed consent prior to participation.

\section{Sample Size}

Sample size was determined based on a nominal 2-sided type I error rate of $5 \%$ and $80 \%$ power. Estimates of standard deviation in $\mathrm{HbA}_{1 \mathrm{c}}$ ranging from $0.50 \%$ to $0.75 \%$ were used to determine the minimum number of participants required to detect a clinically relevant $(\geq 0.5 \%)$ change in $\mathrm{HbA}_{1 \mathrm{c}}$ levels [34-36]. Standard deviation estimations were consistent with the bant pilot study, which reported a baseline standard deviation of $0.55 \%$ in $\mathrm{HbA}_{1 \mathrm{c}}$ levels, and were also informed by longitudinal $\mathrm{HbA}_{1 \mathrm{c}}$ variation over 9 months in an independent sample of 13 patients. A final sample size of 92 participants (46 per intervention arm) allowed for a potential $25 \%$ dropout rate.

\section{Random Allocation}

At enrollment, participants were assigned equally to an intervention or control arm using randomly allocated block sequences of 4 to 6 participants. To ensure equal distribution between arms, we stratified random allocation for treatment modality (insulin pump vs insulin injection), as well as study center (The Hospital for Sick Children vs Trillium Health Partners). The RCT was an unblinded, open-label study, as both the participants and those delivering the intervention were aware of allocation based on whether or not the bant system was received. In addition, clinical outcomes were not blinded, as they are part of a participant's ongoing clinical care and diabetes monitoring regimen.

\section{Intervention}

The initial design of bant was informed by insights gathered through qualitative ethnographic interviews conducted with adolescents living with type 1 diabetes and their families. In addition to patient input, we held focus group sessions with clinical staff who had experience managing type 1 diabetes and chronic disease among adolescents. Feedback from these sessions, as well as input from human factors specialists, informed the development of the pilot version of bant, which was then evaluated among 20 adolescents for 3 months. The initial focus group sessions, user-centered design, and evaluation of bant have been previously reported by Cafazzo et al [32]. Upon the completion of the pilot trial, we obtained feedback from participants, leading to further refinement of bant (Multimedia Appendix 2). It is important to note that, while the pilot version of bant was designed to incentivize more frequent SMBG, the updated version of bant included additional tactics that could potentially further facilitate improved $\mathrm{HbA}_{1 \mathrm{c}}$. Therefore, users were rewarded for taking SMBG but also for maintaining their blood glucose within their target range. Table 1 describes the key features of bant (for related screenshots, see Multimedia Appendix 2), and Figure 1 illustrates the system that the intervention group received. 
Table 1. Key features of bant.

\begin{tabular}{ll}
\hline Feature & Description \\
\hline Automatic Data Transfer & $\begin{array}{l}\text { Blood glucose readings are wirelessly transferred from a Bluetooth-enabled blood glucose meter, using an } \\
\text { adaptor (BluGlu), to bant. }\end{array}$ \\
Electronic Logbook & $\begin{array}{l}\text { Current and past blood glucose readings categorized by context (eg, lunch) are displayed over multiple time } \\
\text { frames (eg, 1 week, } 1 \text { month). }\end{array}$ \\
Trends & $\begin{array}{l}\text { Percentages of readings in or out of target, per context, are displayed over various time frames (eg, over 30 } \\
\text { days, } 10 \% \text { of breakfast readings were high). }\end{array}$ \\
Trend Wizard & $\begin{array}{l}\text { Algorithm that detects and informs the user of consecutive out-of-range readings for the same context (eg, } 3 \\
\text { consecutive high dinner readings) and prompts the user to identify the likely cause of the trend and potential } \\
\text { fixes. }\end{array}$ \\
Reward System & $\begin{array}{l}\text { Reward mechanism that awards points to encourage the following behaviors: (1) taking up to } 5 \text { readings per } \\
\text { day, (2) getting readings in target range, (3) avoiding out-of-range trends, and (4) resolving any identified 3-day } \\
\text { trends. }\end{array}$ \\
Users can redeem their points for iTunes gift cards. \\
bant also includes a leaderboard for users to see where they rank compared with their peers. \\
A private social media community that allowed trial participants to communicate with each other. \\
Integration with TELUS health space, a secure personal health record that stored blood glucose data and enabled \\
sharing with members of the care team.
\end{tabular}

Figure 1. The intervention includes an iPhone $4 \mathrm{~S}$ loaded with bant, as well as a Bluetooth adapter attached to the OneTouch UltraMini blood glucose meter. Circles represent individual readings at different times of the day, with the bedtime reading having been selected to display further information; the blue region represents a particular participant's target blood glucose range. The different colors of the circles represent the different reading contexts (eg, breakfast readings are blue).

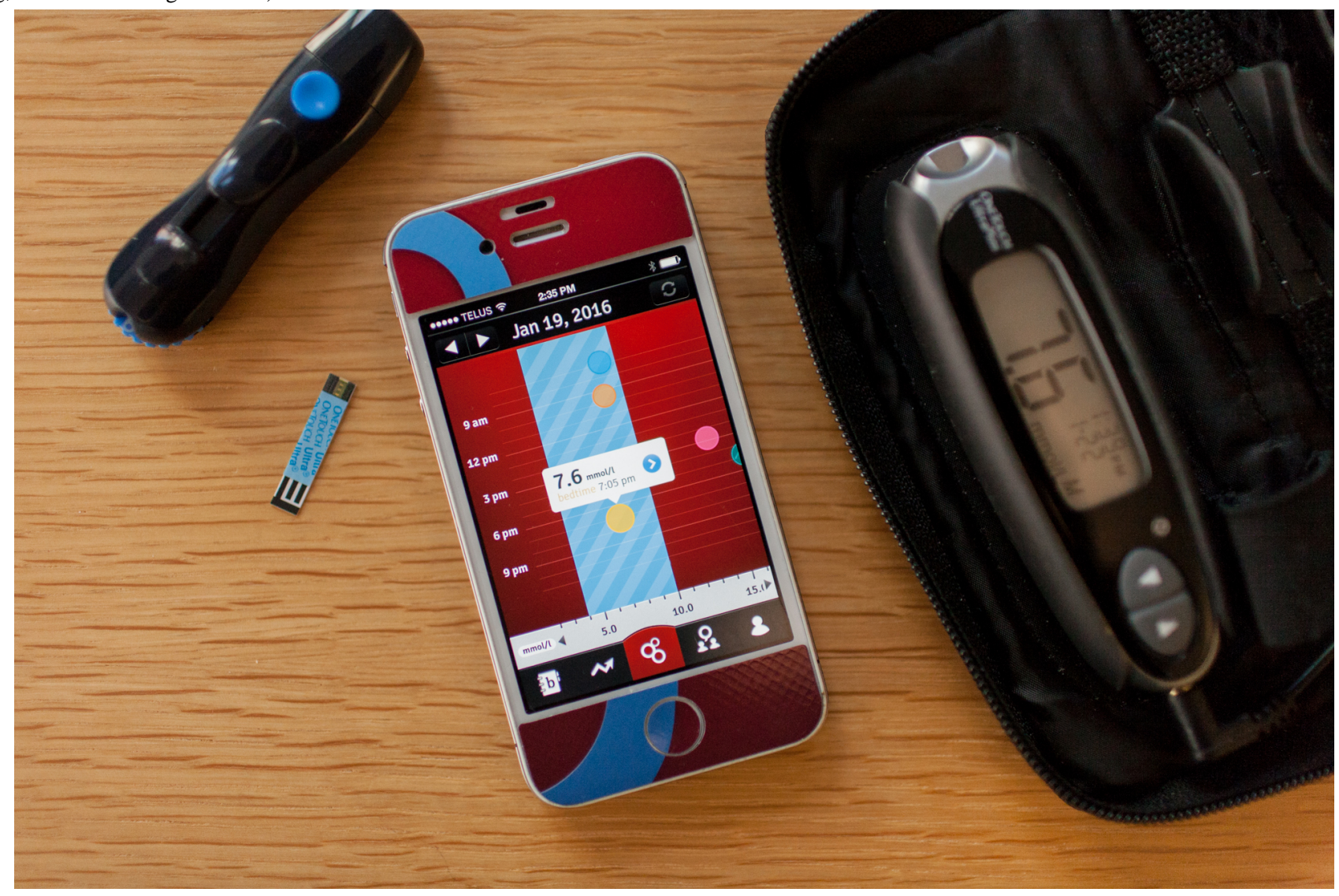

\section{Study Protocol}

Adolescents who met the inclusion criteria and provided informed consent were randomly allocated to receive either usual clinical care (control group) or usual clinical care plus bant (intervention group). For reference, usual clinic care was defined as the standard care all youth and adolescents with type 1 diabetes receive at their quarterly clinic visits, as dictated by Canadian Diabetes Association guidelines [31]. At baseline, those allocated to the intervention group received an iPhone $4 \mathrm{~S}$ (Apple Inc, Cupertino, CA, USA) loaded with bant, a OneTouch UltraMini (Lifescan, Inc, Milpitas, CA, USA) blood glucose 
meter, and a Bluetooth adapter (BluGlu, a device developed by University Health Network for investigational purposes only) that allowed for wireless transmission of data from the blood glucose meter to bant. To facilitate independent use, all bant users received a standardized 1-hour tutorial at study enrollment, which included hardware setup, introduction to app features, username creation, and troubleshooting steps for potential issues. During this time, bant users also created a TELUS health space account (TELUS Health Solutions, Cambridge, ON, Canada), which allowed for remote and secure storage and backup of their blood glucose data. Control group participants also completed a baseline visit. However, they did not receive any study-related hardware from the research team. Both control and intervention participants received 2 movie theater passes in exchange for their effort and time during the baseline and all subsequent visits.

Baseline visits were followed by 3-, 6-, 9-, and 12-month research visits for all participants. All research visits coincided with the participant's standard quarterly clinic visit; however, these visits were conducted separate from the clinic visit by trained research staff. Qualitative and quantitative data were collected at all follow-up visits via semistructured interviews, validated instruments, downloads of blood glucose meters, and electronic chart review. Halfway between each follow-up visit, we contacted participants in the bant group to ensure they were not experiencing any technical issues. No advice or communication around clinical care or their diabetes regimen was discussed with participants during these calls. At study end, the bant system was returned to research personnel.

\section{Primary Outcome Measures}

The primary outcome of the study was change in $\mathrm{HbA}_{1 \mathrm{c}}$ (measured in percentage) from baseline to 12 months, between the intervention and control group. $\mathrm{HbA}_{1 \mathrm{c}}$ was measured during routine clinical blood work and accessed by research staff through electronic chart review. The primary research site (The Hospital for Sick Children) used a high-performance liquid chromatography assay (Bio-Rad Laboratories, Inc, Waterloo, ON, Canada) or an enzymatic assay (Abbott Laboratories, Ltd, North York, ON, Canada) to measure $\mathrm{HbA}_{1 \mathrm{c}}$, with internal quality control demonstrating excellent agreement among samples assayed by both methods $(r>.99)$. The secondary site (Trillium Health Partners) measured $\mathrm{HbA}_{1 \mathrm{c}}$ using a point-of-care immunoassay (DCA 2000+, Siemens Healthcare Ltd, Oakville, ON, Canada) for all measurements.

\section{Secondary Outcome Measures}

\section{Hypoglycemic Events}

The frequency of mild and severe hypoglycemic events was assessed as secondary measures of glycemic control. A severe hypoglycemic event was defined as any episode that required the assistance of another individual and a blood glucose reading below $2.8 \mathrm{mmol} / \mathrm{L}$ and/or a subsequent reversal of clinical symptoms with intake of oral carbohydrate, glucagon injection, or intravenous glucose [37]. A mild hypoglycemia event was defined as a blood glucose reading below $3.4 \mathrm{mmol} / \mathrm{L}$.
The frequency of severe hypoglycemic events was self-reported by participants and/or their guardians during semistructured interviews conducted at baseline and all follow-up research visits. To capture the frequency of mild hypoglycemic events, the previous 50 days of blood glucose readings were downloaded from all available (study and/or personal) blood glucose meters and/or insulin pumps during the participant's clinic appointment. All downloads were completed by trained staff using the manufacturer-provided electronic downloading programs, specific to each blood glucose meter or pump brand. In cases where not all hardware was available, participants estimated what percentage of their total blood glucose readings were on the devices they brought to clinic that day.

All individual readings below $3.4 \mathrm{mmol} / \mathrm{L}$ were recorded as an individual mild hypoglycemic event, except for low blood glucose readings taken within the same or consecutive-hour timeslots. Grouping contemporaneous readings together and counting them as a single episode ensured that a singular hypoglycemic event was not recorded multiple times.

\section{Self-Monitoring of Blood Glucose}

We measured the average number of daily SMBG using all data collected from the 50-day blood glucose meter and/or insulin pump printout(s). Each blood glucose reading was counted individually, except when taken within the same hour, in which case readings were grouped. Readings taken over a 2-hour period in apparent response to an initial low $(<4.1 \mathrm{mmol} / \mathrm{L})$ or high $(>17.9 \mathrm{mmol} / \mathrm{L})$ were also grouped together. Using the total counted readings and number of days collected, we calculated the average number of daily SMBG at baseline as well as each follow-up visit, and when warranted, corrected for the percentage of readings available as estimated by participants.

\section{Self-Initiated Adjustments}

We assessed the number of self-initiated adjustments made to a participant's type 1 diabetes insulin regimen during qualitative interviews conducted at baseline and all follow-up visits to determine whether use of bant led participants to attempt to adjust their insulin regimens more frequently. A self-initiated adjustment was defined as a change made to the prescribed treatment regimen that was initiated by the participant and/or their guardian(s) and implemented between clinic appointments. Changes made to the regimen by the diabetes care team during a routine clinic visit were not included. Participants self-reported who (the participant and/or their parent[s]/guardian[s]) was responsible for initiating the adjustment(s), as well as whether the diabetes team had been contacted for input on the regimen change.

\section{Validated Questionnaires}

Validated instruments were used to capture quality of life, self-care, and management data. The Diabetes Quality of Life for Youth (DQOLY) questionnaire [38,39] and the Diabetes Family Responsibility Questionnaire (DFRQ) [40] were administered at 6- and 12-month visits; the Self Care Inventory [41-43] was administered at all time points. The Readiness to Change Survey (Multimedia Appendix 3, Participant Management Questionnaire) was captured at baseline to help characterize the study population $[44,45]$. All surveys were 
given to participants to complete independently during their research visit.

\section{Satisfaction With bant}

We assessed overall satisfaction with bant via qualitative interviews conducted at 6- and 12-month visits. On a 7-point Likert scale, ranging from 1 (very dissatisfied) to 7 (very satisfied), users were asked to rate overall satisfaction as well as satisfaction for 5 individual bant components: (1) trend wizard, (2) the leaderboard, (3) automatic blood glucose transfer, (4) banter, and (5) iTunes rewards. In addition to collecting satisfaction scores, we conducted semistructured interviews to gather qualitative feedback from bant users during their 6- and 12 -month research visits. Users were asked to provide feedback on app features, content, and how bant influenced their overall type 1 diabetes management. They were also asked to list, in a free-form text field, the 3 most and least helpful features of bant.

\section{Usage Data}

We collected mobile usage data through a third-party service, Flurry (Yahoo, Sunnyvale, CA, USA), which tracked (1) the number of times users accessed bant, (2) how often they used certain features, and (3) the number of times users wirelessly uploaded data from their blood glucose meter.

\section{Statistical Analysis}

Preliminary $t$ tests and chi-square tests were used to determine if there were any statistically significant differences between the intervention and control groups for the primary and secondary outcomes and demographic characteristics at baseline. This step allowed us to ensure the comparability of both the intervention and control groups at baseline and to ensure that we did not have any chance imbalances that might have required further adjustment.

Subsequently, we used linear mixed models to determine whether there were any statistically significant differences between the treatment and control groups for the above-mentioned outcomes. As all outcomes of interest were continuous, a linear mixed-model approach provided a simple method to assess treatment efficacy while adjusting for the correlation of each participant over time (using a random effect). Moreover, this approach is more powerful than a repeated-measures analysis of variance (ANOVA), as it allows participants with missing values at 1 or more time points to contribute some information to the analysis, while a repeated-measures ANOVA requires the availability of data at all time points for each participant [46]. We examined each outcome graphically to determine whether the data were normally distributed. All outcomes were approximately normally distributed, with the exception of the number of mild hypoglycemic events, which appeared to be somewhat skewed. However, linear mixed models have the ability to assess data that are not normally distributed and remain robust, as long as the sample size is large [47]. As a result of the large sample size and graphical appearances of normality, this assumption appeared reasonable.

Secondary analyses relied on comparison between groups at the primary end point of 12 months using 2-sample $t$ tests or chi-square tests. Moreover, additional exploratory univariate regression analyses examined the impact of SMBG on clinical outcomes for those who were taking SMBG 5 or more times per day at 12 months within both the intervention $(n=8)$ and control $(n=5)$ groups. Although this is a very small subgroup, it provides some insight into the potential role of bant in controlling diabetes for those participants who are engaged and actively monitoring their blood glucose levels. Due to small sample sizes, adjusting for other confounding variables was not possible. Additionally, we used exploratory analyses, including chi-square tests, 2-sample $t$ tests, and regression analyses, to evaluate the effectiveness of bant in subgroups based on insulin regimen (insulin pump vs insulin injections) and baseline $\mathrm{HbA}_{1 \mathrm{c}}$ levels ( $\geq 9.0 \%$ vs $<9.0 \%$ ). Finally, usage and satisfaction data were also summarized for exploratory purposes. All statistical analyses were performed using SAS software version 9.4 for Windows (SAS Institute) Results were considered statistically significant at the $P \leq .05$ level, and all reported results are 2-tailed.

\section{Results}

\section{Study Population}

Using the study inclusion criteria, we identified eligible participants from clinical databases and enrolled them sequentially until recruitment targets were met. Through this process, 199 eligible patients were identified; 42 patients declined to participate, 31 patients no longer met eligibility criteria, and 34 patients were excluded for other reasons, including planning to change clinics within the study time frame, having recently switched insulin regimens, and participating in another study with similar outcome measures. As Figure 2 shows, a total of 92 participants were enrolled and randomly allocated into the study.

Table 2 summarizes the demographic characteristics of the participants at baseline. There were no significant differences between the 2 groups in any of the measured characteristics, nor were there significant differences between the groups with respect to the readiness to change domains. 
Table 2. Baseline characteristics of intervention and control groups.

\begin{tabular}{llll}
\hline Characteristics & Treatment group (n=46) & Control group (n=46) & $P$ value \\
\hline Sex (male/female), $\mathrm{n}$ & $21 / 25$ & $20 / 26$ & $>.99$ \\
Age at baseline in years, mean (SD) & $14.1(1.7)$ & $13.9(1.5)$ & .54 \\
Age at diagnosis in years, mean (SD) & $7.1(3.6)$ & $7.4(3.3)$ & .71 \\
Duration of type 1 diabetes mellitus in years, mean (SD) & $7.1(3.2)$ & $6.6(3.2)$ & .48 \\
Insulin regimen (pump/injection), $\mathrm{n}$ & $23 / 23$ & $22 / 24$ & .84 \\
Hemoglobin $\mathrm{A}_{1 \mathrm{c}}$ in $\%$, mean (SD) & $8.96(0.7)$ & $8.92(0.6)$ & .77 \\
\hline
\end{tabular}

Figure 2. Participant enrollment.

\section{Met eligibility criteria}

46 Enrolled into Intervention Arm

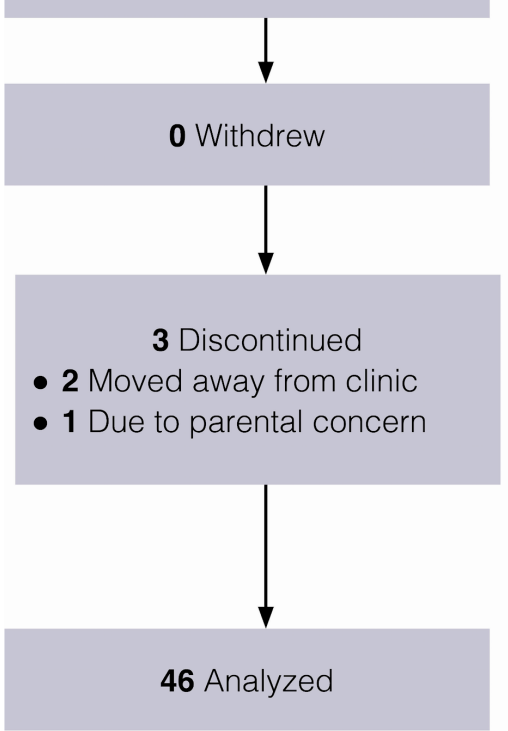

\section{Clinical Outcomes}

There were no significant differences in $\mathrm{HbA}_{1 \mathrm{c}}$ between the intervention and control groups over the duration of the 12-month trial $(P=.99)$. Both groups demonstrated diminution in $\mathrm{HbA}_{1 \mathrm{c}}$ up to the 9-month time point, after which both experienced a subsequent increase to preintervention $\mathrm{HbA}_{1 \mathrm{c}}$ levels. This diminution speaks to study effects from the trial
107 Excluded

42 declined to participate

31 were no longer eligible

- 34 other reasons

92 Enrolled into Study

\section{Enrolled into Control Arm}

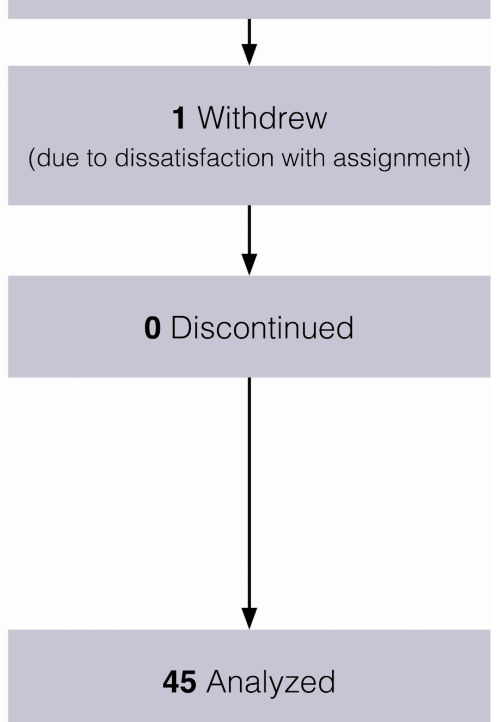

and demonstrates the importance of the control group. At trial conclusion, the intervention and control group displayed a mean $\mathrm{HbA}_{1 \mathrm{c}}$ of $8.96( \pm 1.3)$ and $\mathrm{HbA}_{1 \mathrm{c}}$ of $8.96( \pm 1.2)$, respectively (Figure 3).

Between group analyses also showed no significant improvements in any of the predefined secondary outcomes between the intervention and control groups (Table 3). 
Table 3. Secondary outcome measures.

\begin{tabular}{|c|c|c|c|c|c|}
\hline \multirow[t]{2}{*}{ Outcome measures } & \multicolumn{2}{|l|}{ Intervention } & \multicolumn{2}{|l|}{ Control } & \multirow{2}{*}{$\begin{array}{l}P \text { value (between } \\
\text { group) }\end{array}$} \\
\hline & Baseline & 12 months & Baseline & 12 months & \\
\hline Mild hypoglycemic events ${ }^{\mathrm{a}}$, mean (SD) & $10(8.2)$ & $11.52(10.7)$ & $8.49(9.6)$ & $7.54(7.7)$ & .047 \\
\hline Severe hypoglycemic events ${ }^{\mathrm{b}}$, mean (SD) & $0.23(0.6)$ & $0.16(0.4)$ & $0.41(1.3)$ & $0.48(1.2)$ & .13 \\
\hline Self-monitoring blood glucose ${ }^{\mathrm{a}}$, mean (SD) & $3.98(1.6)$ & $3.49(1.8)$ & $3.55(1.6)$ & $3.39(1.5)$ & .42 \\
\hline Number of adjustments to regimen ${ }^{\mathrm{b}}$, mean (SD) & $1.85(2.3)$ & $1.77(2.7)$ & $2.08(3.4)$ & $1.10(1.3)$ & .25 \\
\hline SCI score ${ }^{c}$, mean (SD) & $35.73(4.6)$ & $35.42(5.0)$ & $36.07(5.4)$ & $35.57(6.4)$ & .81 \\
\hline \multicolumn{6}{|l|}{ DQOLY $^{\mathbf{d}}$ subscale scores, mean (SD) } \\
\hline Impact of Symptoms & $3.58(1.7)$ & $3.33(1.7)$ & $3.55(1.8)$ & $3.16(1.6)$ & .15 \\
\hline Impact of Treatment & $2.76(2.3)$ & $2.53(2.1)$ & $2.73(2.0)$ & $2.28(2.2)$ & .51 \\
\hline Impact on Activities & $3.00(2.2)$ & $2.96(3.0)$ & $3.04(2.8)$ & $3.42(3.0)$ & .72 \\
\hline Parental Issues & $5.13(3.3)$ & $5.20(3.6)$ & $5.12(3.1)$ & $4.67(3.6)$ & .71 \\
\hline Worries About Diabetes & $6.83(5.5)$ & $6.84(5.8)$ & $6.51(5.8)$ & $4.81(5.0)$ & .17 \\
\hline Health Perception & $2.00(0.7)$ & $1.96(0.7)$ & $1.90(0.6)$ & $2.10(0.6)$ & .50 \\
\hline \multicolumn{6}{|l|}{ DFRQ $^{\mathrm{e}}$ overall and subscale scores, mean (SD) } \\
\hline General Health Domain & $12.76(2.2)$ & $13.70(2.4)$ & $12.53(2.1)$ & $13.31(2.8)$ & .60 \\
\hline Social Presentation Domain & $8.62(1.6)$ & $8.86(1.5)$ & $8.81(1.5)$ & $9.08(1.4)$ & .38 \\
\hline Regimen Domain & $13.90(2.4)$ & $14.60(2.1)$ & $13.61(2.5)$ & $14.40(2.7)$ & .64 \\
\hline Total DFRQ score & $35.29(4.9)$ & $37.16(4.3)$ & $34.94(4.6)$ & $36.79(5.7)$ & .78 \\
\hline
\end{tabular}

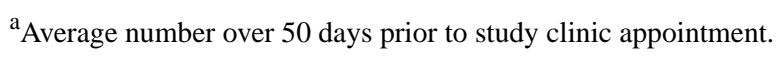

${ }^{\mathrm{b}}$ Average number between study clinic appointments (typically 90 days).

"SCI: Self-Care Inventory, a 14-item questionnaire using 6-point scale (1 to 5, and "not applicable" option) to measure adherence to treatment recommendations. Overall score ranges from 10 to 50.

${ }^{\mathrm{d} D Q O L Y: ~ D i a b e t e s ~ Q u a l i t y ~ o f ~ L i f e ~ f o r ~ Y o u t h ~ q u e s t i o n n a i r e, ~ a ~ 22-i t e m ~ q u e s t i o n n a i r e ~ m e a s u r i n g ~ q u a l i t y ~ o f ~ l i f e, ~ s p l i t ~ a c r o s s ~} 6$ subscales. Subscales use an inverted 5-point Likert scale (0 to 4), with the exception of the Health Perception subscale, which uses an inverted 4-point scale (1 to 4). Higher scores are associated with poorer quality of life; possible subscale scores range from 1 to 4 (Health Perception), 0 to 12 (Impact of Symptoms, Impact of Treatment, Parental Issues), 0 to 20 (Impact on Activities), and 0 to 28 (Worries About Diabetes).

eDFRQ: Diabetes Family Responsibility Questionnaire, a 17-item questionnaire measuring adolescent-guardian interaction around care, split across 3 subscales. All subscales use a 3-point scale (1 to 3). Higher scores are associated with increased adolescent involvement in care. Overall score ranges from 17 to 51; subscales range from 7 to 21 (General Health Domain), 4 to 12 (Social Presentation Domain), and 6 to 18 (Regimen Domain). 
Figure 3. Mean hemoglobin $A_{1 c}$ values for the intervention and control groups from baseline to 12 months.

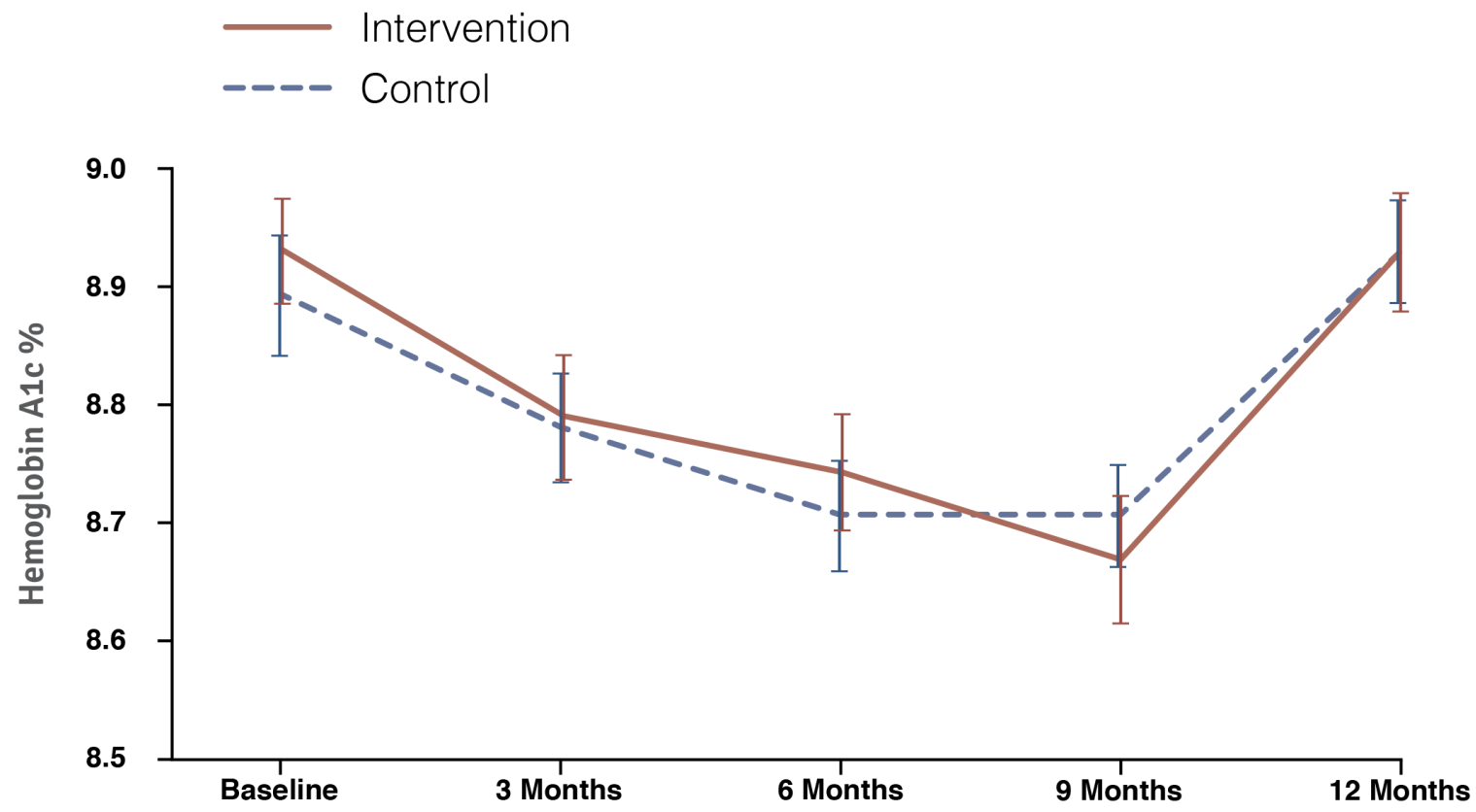

Visits

\section{Exploratory Analyses}

Using all available data at each time point, we performed additional analyses to identify potential relationships between measured clinical outcomes, both within and between the intervention and control groups. Figure 4 shows a significant relationship between increased SMBG and improved $\mathrm{HbA}_{1 \mathrm{c}}$ in the intervention group at baseline, which strengthened over time, specifically when comparing 9-month $(P=.002)$ and 12 -month visits $(P=.008)$ with baseline. This relationship was not observed in the control group at any time point (n between 32 and 46 for comparison).

In further exploratory analyses, we identified a subgroup of patients with a frequency of SMBG of 5 or more per day at 12 months within both the intervention $(n=8)$ and control $(n=5)$ groups. This threshold was chosen because it is a commonly recommended daily SMBG target in The Hospital for Sick Children diabetes clinic, and this group represented a population of users who were actively engaged with daily SMBG at the end of the trial. No significant difference in daily SMBG was noted between the control subgroup (mean 7.02, SE 0.57) and the intervention subgroup (mean 6.32, SE 0.45) at baseline
$(P=.34)$. Similarly, at 12 months, there was also no significant difference in SMBG frequency between participants in the control (mean 6.24, SE 0.57) and intervention (mean 6.33, SE $0.45)$ subgroups $(P=.90)$.

$\mathrm{HbA}_{1 \mathrm{c}}$ did not significantly differ between the 2 subgroups at baseline (control mean $8.84 \%$, SE $0.27 \%$ vs intervention mean $8.40 \%$, SE $0.21 \% ; P=.21)$. However, as shown in Figure 5, at the 6-month time point, users in the intervention subgroup demonstrated a significantly lower $\mathrm{HbA}_{1 \mathrm{c}}$ when compared with the controlled subgroup $(P<.001)$, a difference that persisted for the remainder of the trial (9 months, $P<.001 ; 12$ months, $P=.008)$. Furthermore, the bant subgroup demonstrated an overall improvement in $\mathrm{HbA}_{1 \mathrm{c}}$ of $0.58 \%(P=.02)$, while the parallel subgroup in the control arm experienced no significant change in $\mathrm{HbA}_{1 \mathrm{c}}$ (decrease of $0.06 \%, P=.84$ ).

In addition to the subset with SMBG of 5 or more per day, we also conducted subgroup analyses for insulin regimen (insulin pump vs insulin injections), as well as baseline $\mathrm{HbA}_{1 \mathrm{c}}$ levels (participants with baseline $\mathrm{HbA}_{1 \mathrm{c}} \geq 9.0 \%$ vs $<9.0 \%$ ); however, no statistically significant differences were noted. 
Figure 4. Regression analysis for self-monitoring of blood glucose (SMBG) and hemoglobin $A_{1 c}$.

\section{Intervention Group}

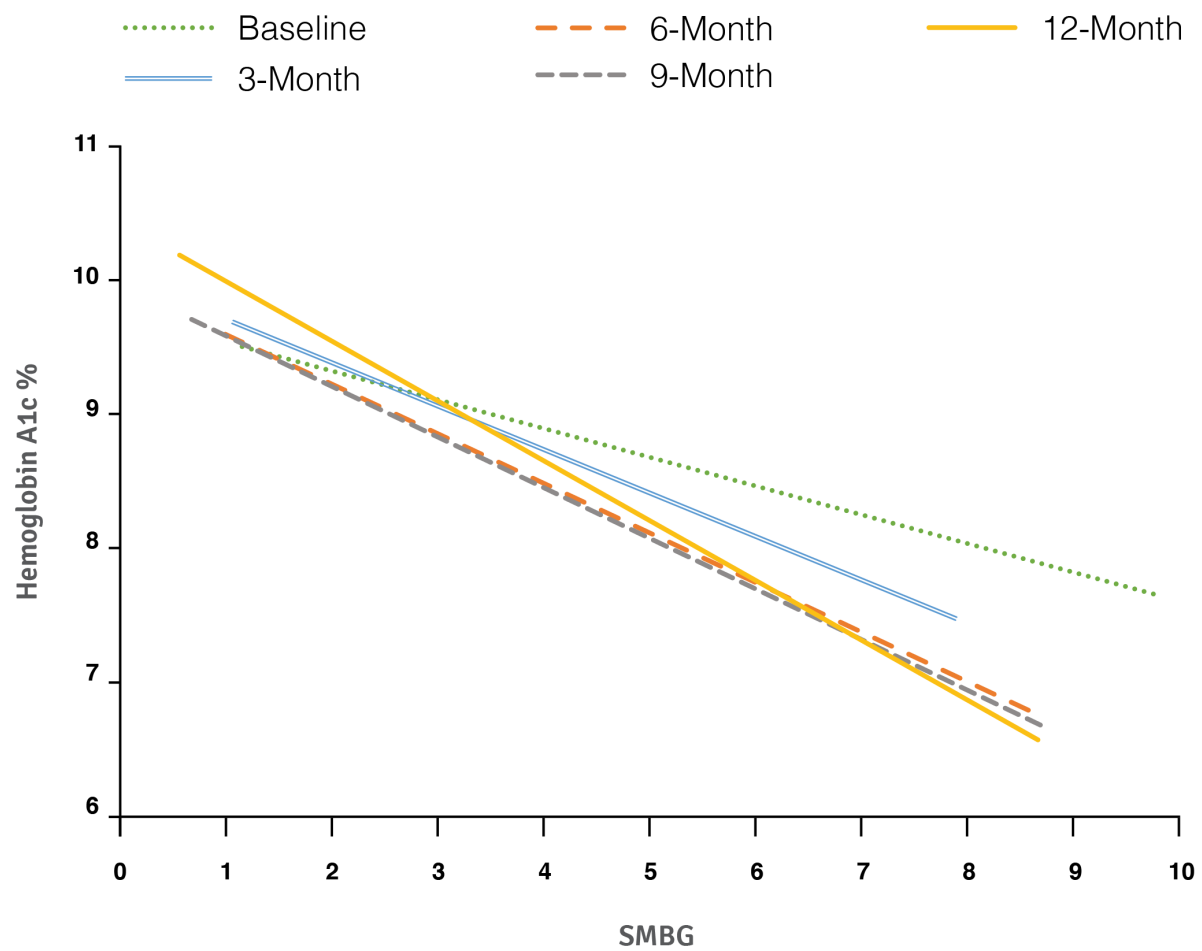

Control Group

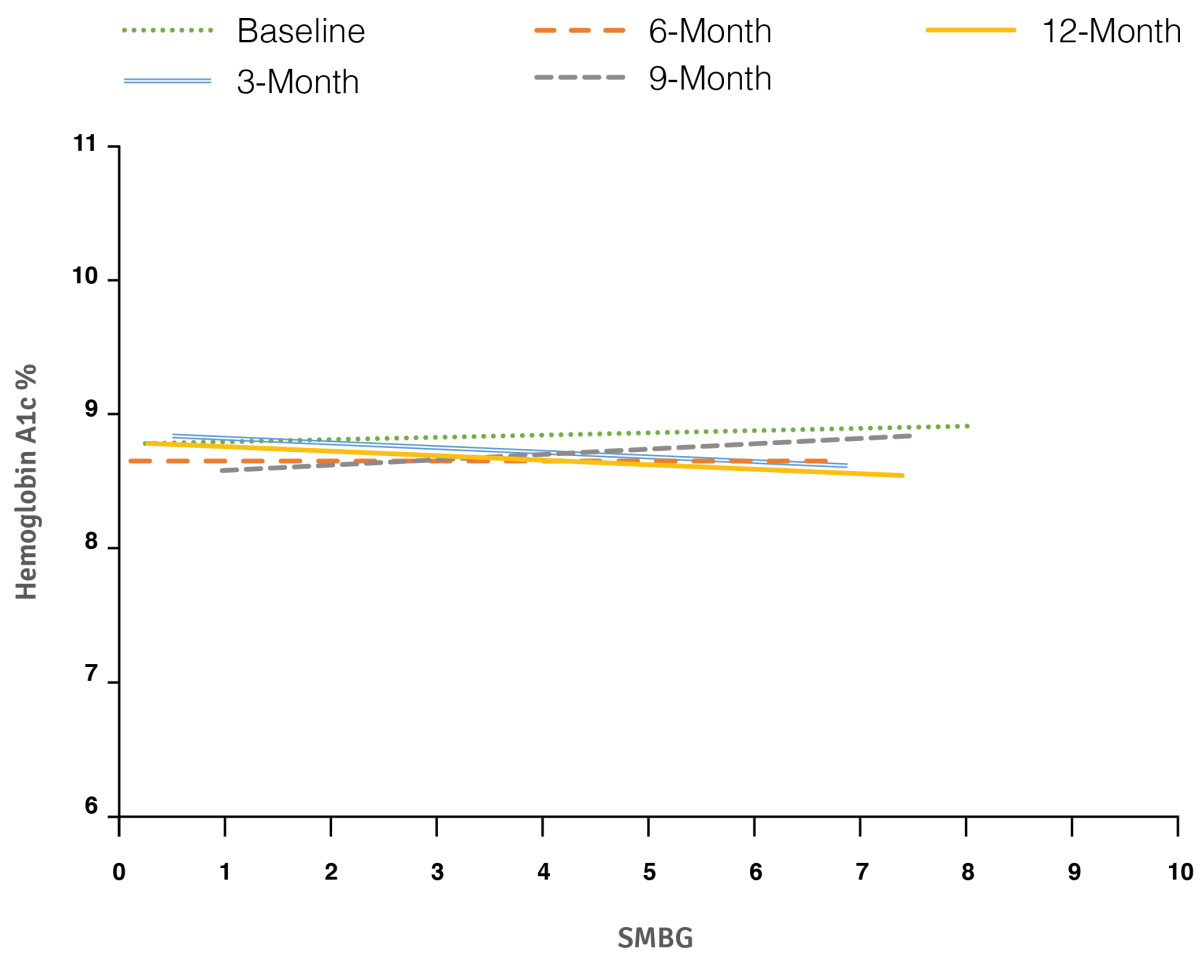


Figure 5. Longitudinal mean hemoglobin $A_{1 c}$ for intervention and control participants with 12-month self-monitoring of blood glucose of 5 or more per day.

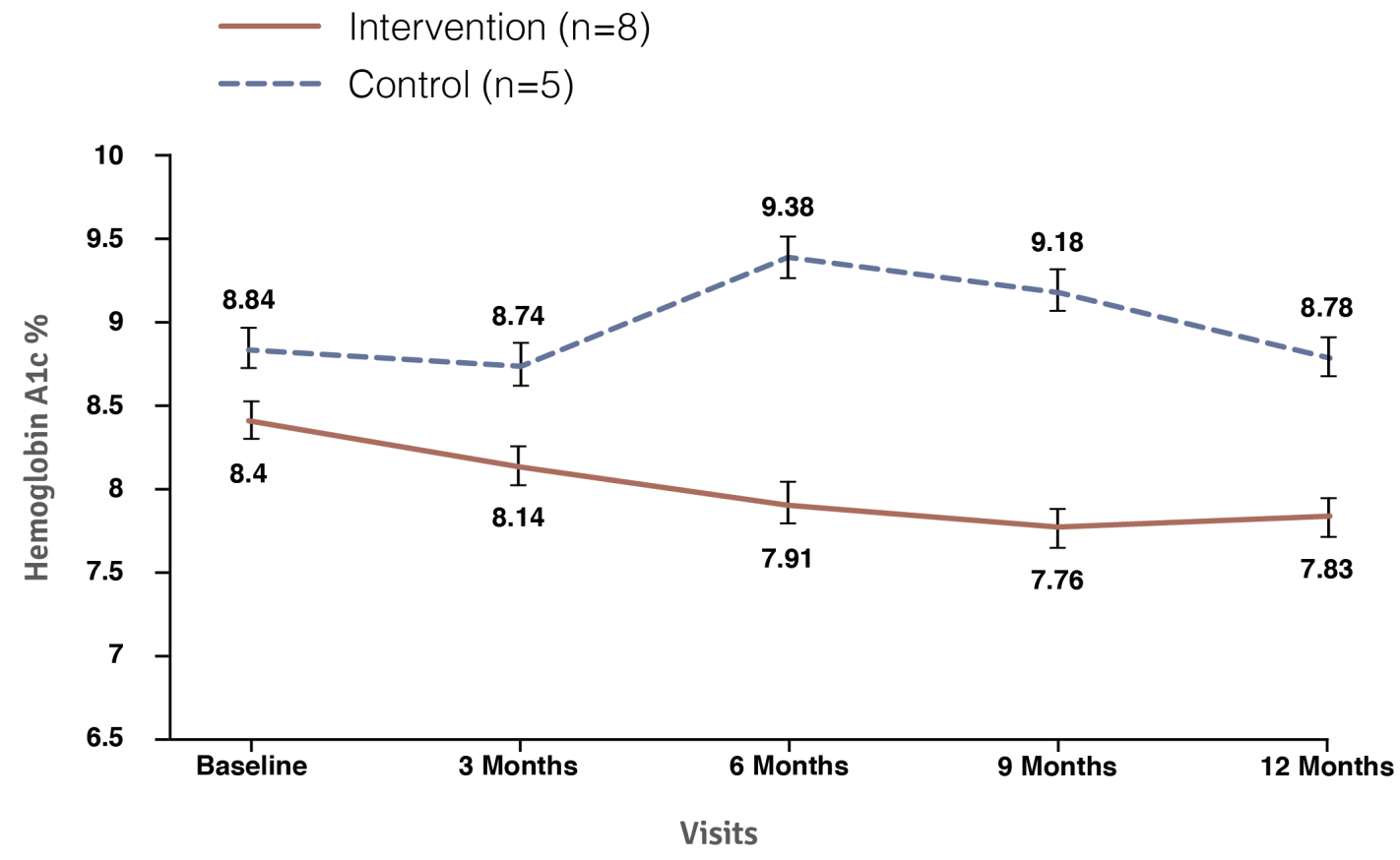

\section{bant Usage Data}

To assess use of bant over the course of the study, engagement levels were established. Given that the app was designed to facilitate daily SMBG and self-management activities, the engagement threshold levels were based on the total number of days that a user wirelessly uploaded blood glucose readings to bant over 12 months. As Table 4 shows, 4 levels of engagement (very low, low, moderate, and high) were used, where the highest engagement level was defined by a data upload frequency greater than 3 out of 7 days.

Table 4. Engagement thresholds, determined by the frequency of reading uploads, during the 12-month trial ( $\mathrm{n}=46)$.

\begin{tabular}{llllll}
\hline Engagement levels & Definitions & Injections (n) & Insulin pump (n) & Total (n) & $\begin{array}{l}\% \text { of all participants within } \\
\text { each threshold }\end{array}$ \\
\hline Very low & Less than 1 of 14 days & 9 & 8 & 17 & 37 \\
Low & Less than 1 of 7 days & 6 & 7 & 13 & 28 \\
Moderate & Less than 3 of 7 days & 5 & 7 & 12 & 26 \\
High & 3 of 7 days or more & 3 & 1 & 4 & 9 \\
Total & & 23 & 23 & 46 & 100
\end{tabular}

Overall, usage of bant showed a significant interaction with $\operatorname{SMBG}(P=.03)$, with users in the high-engagement group having a significantly higher frequency of SMBG throughout the trial than users with either low $(P=.004)$ or very low engagement $(P=.02)$. Further analyses demonstrated no significant association between bant usage and any other clinical outcomes.

\section{Satisfaction}

Participants reported high levels of satisfaction with bant throughout the trial (Figure 6). At 6 and 12 months, 79\% (30/38) and $76 \%(34 / 45)$ of participants reported being "satisfied" or "very satisfied" with bant, respectively. In addition, 96\% (43/45) of respondents reported that they would continue to use bant if it were available to them outside of the trial.

We also asked users to rank the features of bant according to their perceived usefulness in assisting with daily self-management of type 1 diabetes. Overall, the trending feature was ranked as the most useful component of bant by $45 \%$ (20/44) of respondents. This was followed by the logbook, which was ranked most useful by $14 \%$ (6/44), and the app home page (which displays current readings with respect to target range), which was ranked most useful by $11 \%(5 / 44)$. 
Figure 6. Overall satisfaction with bant at the 6- and 12-month time points.

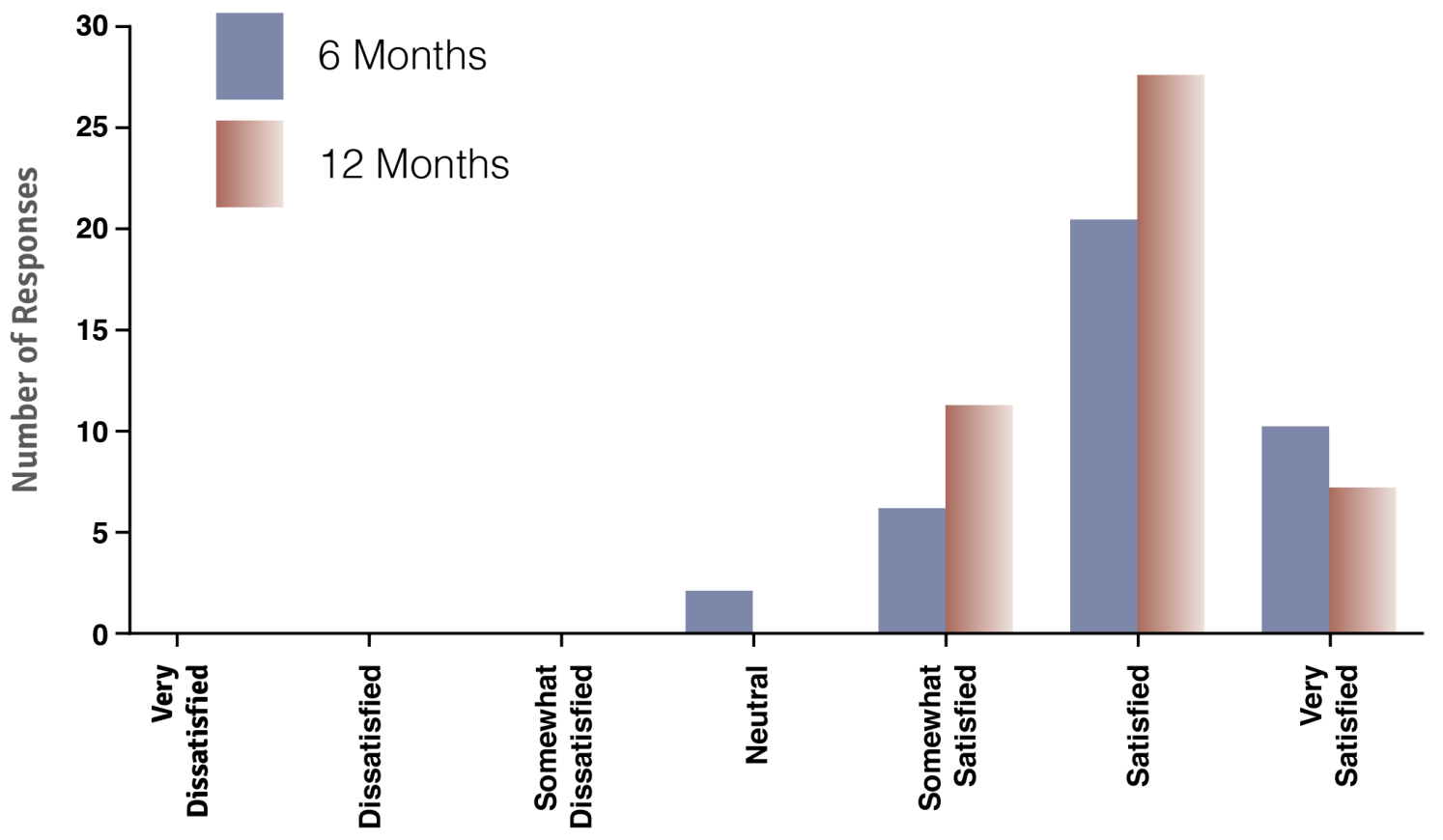

Satisfaction Score

\section{Discussion}

\section{Principal Findings}

The aim of this 12-month RCT was to evaluate the effectiveness of bant, an mHealth app for the self-management of type 1 diabetes among adolescents. Although satisfaction was high across the duration of the trial, with a defined subset of users regularly accessing and using bant, overall we noted no significant improvements in primary or secondary outcomes.

While primary clinical outcomes remained unchanged, a post hoc exploratory analysis provided additional insights. A significant and strengthening relationship between increased SMBG and improved $\mathrm{HbA}_{1 \mathrm{c}}$ was observed exclusively in the intervention group (Figure 4), suggesting that bant users may have better used their SMBG data for the self-management of type 1 diabetes. This finding was reinforced by a subgroup analysis conducted on participants who were taking 5 or more SMBG a day at their 12-month visit. Users in this bant subgroup $(\mathrm{n}=8)$ demonstrated significant improvements in $\mathrm{HbA}_{1 \mathrm{c}}$ when compared with the parallel control subgroup $(n=5)$, with a statistically and clinically significant decrease in $\mathrm{HbA}_{1 \mathrm{c}}$ of $0.58 \%$ over the trial duration. Thus, it is possible that, for those users who were testing frequently, bant enabled better self-management of diabetes, resulting in an improved $\mathrm{HbA}_{1 \mathrm{c}}$, when compared with usual care.

To identify any factors that may have influenced the overall trial results, we conducted several secondary analyses, including the characteristics of the study population and potential trial design artifacts. This RCT purposefully targeted adolescents who were experiencing difficulty in managing their diabetes, as defined by sustained $\mathrm{HbA}_{1 \mathrm{c}}$ values between $8.0 \%$ and $10.5 \%$, who might benefit greatly from enhanced self-management skills and motivation. However, it is possible that, by extending the $\mathrm{HbA}_{1 \mathrm{c}}$ inclusion range to $10.5 \%$, patients whose poor glycemic control was caused by multiple complex factors, requiring support beyond the scope of the bant features, were detrimentally included in the study. While the study was not powered to look at subgroups, we conducted secondary analysis on users with a baseline $\mathrm{HbA}_{1 \mathrm{c}}$ of $9.0 \%$ or more and $\mathrm{HbA}_{1 \mathrm{c}}$ below $9.0 \%$. The results showed no significant changes in glycemic control over the trial duration within either subgroup, suggesting that baseline $\mathrm{HbA}_{1 \mathrm{c}}$ was not predictive of bant's effectiveness.

In addition, with equal numbers of participants on an insulin pump versus insulin injections, it was also possible that the insulin regimen may have affected clinical outcomes. However, secondary subgroup analysis was conducted, which showed no significant impact of bant on glycemic control, or any other clinical outcomes, in either the pump or the injector group.

We also hypothesized that a poorly motivated participant population could have resulted in the lack of improvement in clinical outcomes. However, the Readiness to Change Survey data showed that, on average, the intervention and control groups were classified in similar stages of change at baseline-including the "preparation" stage of change (for increased SMBG), associated with individuals who are ready to implement a plan of action to improve their health outcomes [45]. This observation, paired with the previously discussed subgroup results, suggests that the lack of significance found during primary analysis was likely not due to the demographics of our study population. 
The bant usage data (Figure 7) indicated that, for many of the participants, the regular use of the app extended beyond the average 3- to 5-week engagement period reported by other mobile app industries $[48,49]$. This finding is in accord with the satisfaction data (Figure 6), and implies that future versions of bant may also be well used. However, over the 12-month trial duration, only $35 \%$ of users $(n=16)$ wirelessly uploaded blood glucose data to bant, on average, once or more per week (Table 4). Given that the key self-management features of bant require blood glucose data, it can be inferred that usage of the app is dependent on users uploading data in the first place. There are 2 key factors that may have resulted in the low frequency of data uploads and are recognized limitations of the currently assessed system: (1) providing patients with a secondary mobile phone, and (2) the functionality of BluGlu.

First, participants in the intervention arm were given bant on a study-provided mobile phone, rather than installing the app directly on their own personal devices. While this was intentional, ensuring that all participants had equitable access to the iOS app, recent data indicate that many of these adolescents likely already owned a mobile phone, and therefore the addition of the study phone may have placed an unanticipated burden on the participant [16]. A key strength of mHealth is the ability to capture data and provide feedback for users via their personal devices, which are embedded into their daily routines. Providing the intervention on an additional secondary phone may have defeated the concept of embedded health interventions, as it is likely that many participants may not have wanted, or be able, to carry 2 mobile phones for 12 months.

Interestingly, in the 2011 study $(\mathrm{n}=20)$, bant elicited a significant increase in SMBG [32]. It can be hypothesized that at this time there were lower levels of mobile device penetration among adolescents, and the novelty of having an iPhone would likely compel participants to use the device as a primary phone. Future studies should deploy mHealth apps directly onto personal mobile phones in order to improve usage and facilitate seamless integration into daily life.

Second, we developed the RCT version of bant before the emergence of Bluetooth-enabled blood glucose meters. As such, we developed our own adapter, BluGlu, to facilitate the wireless upload of data from blood glucose meters to bant. However, this adapter was only compatible with the OneTouch UltraMini blood glucose meter. Throughout the study, a subset of participants continued to use additional blood glucose meters, often of a different brand. Therefore, it is possible that asking participants to use an external adapter, which only worked with one particular blood glucose meter, hindered the full integration of bant into their existing diabetes management routines. Over the duration of the RCT, several Bluetooth-enabled meters came onto the market, enabling a "plug and play" environment. A future consideration is to enable an open ecosystem so that users can have the option of using whichever wireless blood glucose meter suits their specific needs; this flexibility, along with no longer needing an external adapter, may improve use of mobile self-management platforms.
Another aspect that should be considered is the role of caregivers in the self-management activities adolescents perform using mobile tools. One of the key themes that emerged during the initial user-centered design of bant was the desire for adolescents to share their diabetes-related information with parents, peers, and clinic staff [32]. A recent literature review by Deacon et al suggested that mobile interventions that encourage data collection as well as clinician feedback may be more successful at decreasing $\mathrm{HbA}_{1 \mathrm{c}}$ [50]. bant included a feature that allowed users to store their data in TELUS health space, a secure personal health record that allowed them, if desired, to share their data with those within their circle of care. It was not possible to gather data around the use of this feature; however, based on interactions with participants, it is likely that bant was used as a stand-alone self-management tool. The next iteration of bant should explore adding features that easily enable adolescents to receive feedback from caregivers and approaches that integrate the app into routine clinical care.

The study results illustrate the importance of rigorously evaluating mHealth apps, not only for understanding the impact on clinical outcomes and user engagement, but also for assessing the methods used to evaluate these tools. While traditional RCTs have been considered as the "gold standard" for evaluation of interventions, a recent review by Pham et al emphasized that RCTs may not be best suited for the evaluation of rapidly evolving software interventions [23]. Traditional RCTs are lengthy (average 5.5 years from enrollment to publication), expensive, and follow a rigid protocol that might not consider the sociotechnical, personal, and social components of mHealth implementation [23]. Perhaps more important, in the context of apps, they restrict the intervention to a static design and limit the ability to dynamically tailor the intervention based on unique needs of individuals. Future evaluations of bant and other mHealth apps should consider use of alternative research methodologies or adaptive RCT study designs [23]. For example, mPower, one of the first ResearchKit (Apple Inc) -enabled observational mHealth iOS app trials, demonstrated a completely electronic and in-app consent, enrollment, and study intervention, and 48,104 participants downloaded the app within the first 6 months of the public launch. Participants completed questionnaires at predetermined time intervals and used the native functionality of the mobile phone and its sensors to quantify symptoms of Parkinson disease (eg, tapping the screen to evaluate dexterity) [49]. Additionally, the Sequential Multiple Assignment Randomized Trial (SMART) adaptive study design enables the identification of the most effective intervention component sequencing strategy, by evaluating outcomes at predetermined time intervals. In this case, we could allocate groups to a specific combination of bant features and, based on the outcomes at a predetermined time point, alter the intervention according to a feature sequencing protocol, allowing us to rapidly converge on optimal intervention designs based on unique patient trajectories [51]. The Multiphase Optimization Strategy adaptive study design ensures the effectiveness of an intervention's individual components and allows for incremental optimization of an intervention, prior to a full-scale RCT [51]. 


\section{Conclusions}

Robust and scalable research methods, coupled with adaptive RCT study designs, have the potential to reshape mHealth research. These approaches can enable the rigorous evaluation of apps in a more timely manner, while facilitating the rapid and iterative development of an intervention, keeping pace with the rapidly and continuously evolving mHealth landscape.

While adolescents are increasingly accessing technologies to support the self-management of type 1 diabetes, the impact of these tools on clinical outcomes remains unclear. Although this RCT found no changes in primary and secondary outcomes, exploratory analysis demonstrated improved $\mathrm{HbA}_{1 \mathrm{c}}$ among bant users who tested blood glucose more frequently. This suggests that these users gained insights around their SMBG data, which may have led to positive changes in their self-management behavior. Overall satisfaction levels were high, suggesting that app users found utility in bant, specifically in features related to management of out-of-range blood glucose trends. The next iteration of bant will explore features that diminish barriers to use, enable deployment directly to personal mobile phones, are integrated into the daily clinical routine, and enable more frequent feedback from caregivers. Future evaluations of apps for diabetes self-management may also benefit from exploring methodologies that allow for more practical, scalable, and robust evaluation, given the challenges associated with rapidly evolving technology and consumer expectations.

Figure 7. Number of times (measured as days per month) users uploaded blood glucose data to bant across the study duration.

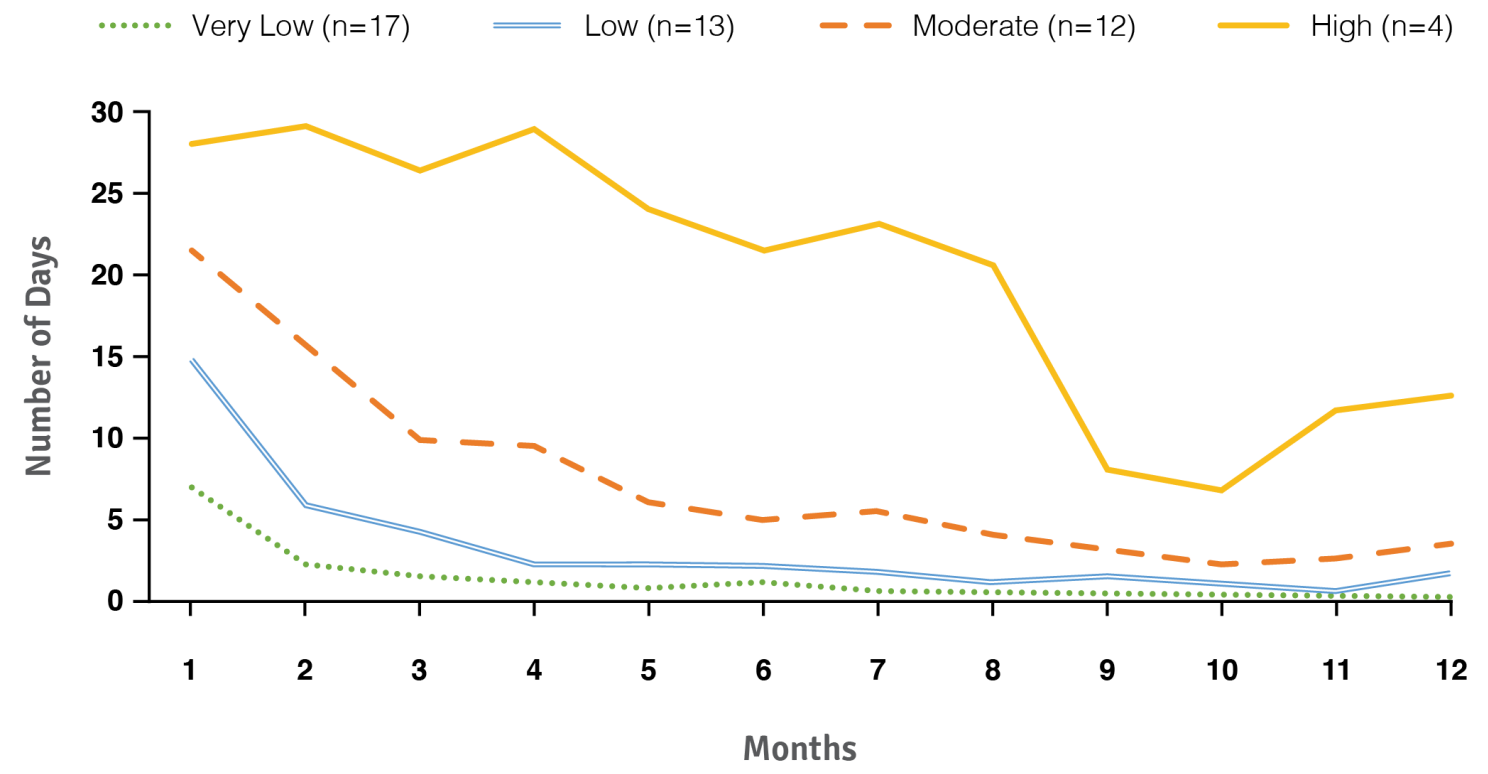

\section{Acknowledgments}

The authors wish to thank the patients and staff of the diabetes clinics at The Hospital for Sick Children (HSC) and Trillium Health Partners for their participation in this study. We are also very grateful to the team (project managers, designers, and software developers) at the Centre for Global eHealth Innovation, University Health Network, for their dedication to the ongoing enhancement and maintenance of bant. We thank Derek Stephens (HSC, Clinical Research Services) and Shiyi Chen (HSC, Clinical Research Services) for their support with statistical analysis and manuscript review. We also acknowledge Katye Stevens for her support with trial execution and Patricia Rego for her technical assistance with data collection. This material is based on work supported by the Thrasher Research Fund, Award \#11054.

\section{Authors' Contributions}

SG and CAN co-led the authorship of the manuscript; CAN led the Introduction and the synthesis of the data collected, SG led the Discussion, and both SG and CAN contributed to the Methods and Results sections. MR and ABC provided the statistical analysis content. DKK, SR, and AS provided guidance with trial development and execution, and edited the manuscript. MRP and JAC were cosupervisors.

\section{Conflicts of Interest}

The Hospital for Sick Children and University Health Network jointly own intellectual property rights to the bant app. Under the respective agreements with their organizations, Joseph A Cafazzo, Mark R Palmert, Debra K Katzman, and Shivani Goyal are entitled to personally benefit from any commercial use of the intellectual property. 


\section{Multimedia Appendix 1}

CONSORT-EHEALTH checklist V1.6.1.

[PDF File (Adobe PDF File), 751KB-Multimedia Appendix 1]

\section{Multimedia Appendix 2}

Overview of the main pages of bant.

[PDF File (Adobe PDF File), 342KB-Multimedia Appendix 2]

\section{Multimedia Appendix 3}

Participant Management Questionnaire.

[PDF File (Adobe PDF File), 235KB-Multimedia Appendix 3]

\section{References}

1. Shulman RM, Daneman D. Type 1 diabetes mellitus in childhood. Medicine 2010 Dec;38(12):679-685. [doi:

10.1016/j.mpmed.2010.09.001]

2. Patterson CC, Gyürüs E, Rosenbauer J, Cinek O, Neu A, Schober E, et al. Trends in childhood type 1 diabetes incidence in Europe during 1989-2008: evidence of non-uniformity over time in rates of increase. Diabetologia 2012 Aug;55(8):2142-2147. [doi: 10.1007/s00125-012-2571-8] [Medline: 22638547]

3. The Diabetes Control and Complications Trial Research Group. The effect of intensive treatment of diabetes on the development and progression of long-term complications in insulin-dependent diabetes mellitus. N Engl J Med 1993 Sep 30;329(14):977-986. [doi: 10.1056/NEJM199309303291401] [Medline: 8366922]

4. Nathan DM, Cleary PA, Backlund JC, Genuth SM, Lachin JM, Orchard TJ, Diabetes Control and Complications Trial/Epidemiology of Diabetes Interventions and Complications (DCCT/EDIC) Study Research Group. Intensive diabetes treatment and cardiovascular disease in patients with type 1 diabetes. N Engl J Med 2005 Dec 22;353(25):2643-2653 [FREE Full text] [doi: 10.1056/NEJMoa052187] [Medline: 16371630]

5. White NH, Cleary PA, Dahms W, Goldstein D, Malone J, Tamborlane WV, Diabetes Control and Complications Trial (DCCT)/Epidemiology of Diabetes Interventions and Complications (EDIC) Research Group. Beneficial effects of intensive therapy of diabetes during adolescence: outcomes after the conclusion of the Diabetes Control and Complications Trial (DCCT). J Pediatr 2001 Dec;139(6):804-812. [Medline: 11743505]

6. Diabetes Control and Complications Trial (DCCT)/Epidemiology of Diabetes Interventions and Complications (EDIC) Study Research Group. Mortality in type 1 diabetes in the DCCT/EDIC versus the general population. Diabetes Care 2016 Aug;39(8):1378-1383. [doi: 10.2337/dc15-2399] [Medline: 27411699]

7. Holl RW, Swift PG, Mortensen HB, Lynggaard H, Hougaard P, Aanstoot H, et al. Insulin injection regimens and metabolic control in an international survey of adolescents with type 1 diabetes over 3 years: results from the Hvidore study group. Eur J Pediatr 2003 Jan;162(1):22-29. [doi: 10.1007/s00431-002-1037-2] [Medline: 12486503]

8. Miller KM, Foster NC, Beck RW, Bergenstal RM, DuBose SN, DiMeglio LA, T1D Exchange Clinic Network. Current state of type 1 diabetes treatment in the U.S.: updated data from the T1D Exchange clinic registry. Diabetes Care 2015 Jun;38(6):971-978. [doi: 10.2337/dc15-0078] [Medline: 25998289]

9. de Beaufort CE, Swift PG, Skinner CT, Aanstoot HJ, Aman J, Cameron F, Hvidoere Study Group on Childhood Diabetes 2005. Continuing stability of center differences in pediatric diabetes care: do advances in diabetes treatment improve outcome? The Hvidoere Study Group on Childhood Diabetes. Diabetes Care 2007 Sep;30(9):2245-2250. [doi: 10.2337/dc07-0475] [Medline: 17540955]

10. Wood JR, Miller KM, Maahs DM, Beck RW, DiMeglio LA, Libman IM, T1D Exchange Clinic Network. Most youth with type 1 diabetes in the T1D Exchange Clinic Registry do not meet American Diabetes Association or International Society for Pediatric and Adolescent Diabetes clinical guidelines. Diabetes Care 2013 Jul;36(7):2035-2037 [FREE Full text] [doi: 10.2337/dc12-1959] [Medline: 23340893]

11. Farmer A, Gibson OJ, Tarassenko L, Neil A. A systematic review of telemedicine interventions to support blood glucose self-monitoring in diabetes. Diabet Med 2005 Oct;22(10):1372-1378. [doi: 10.1111/j.1464-5491.2005.01627.x] [Medline: 16176199]

12. Cameron FJ, de Beaufort C, Aanstoot HJ, Hoey H, Lange K, Castano L, Hvidoere International Study Group. Lessons from the Hvidoere International Study Group on childhood diabetes: be dogmatic about outcome and flexible in approach. Pediatr Diabetes 2013 Nov;14(7):473-480. [doi: 10.1111/pedi.12036] [Medline: 23627895]

13. Miller KM, Beck RW, Bergenstal RM, Goland RS, Haller MJ, McGill JB, T1D Exchange Clinic Network. Evidence of a strong association between frequency of self-monitoring of blood glucose and hemoglobin A1c levels in T1D exchange clinic registry participants. Diabetes Care 2013 Jul;36(7):2009-2014 [FREE Full text] [doi: 10.2337/dc12-1770] [Medline: 23378621] 
14. Skinner H, Biscope S, Poland B, Goldberg E. How adolescents use technology for health information: implications for health professionals from focus group studies. J Med Internet Res 2003 Dec 18;5(4):e32 [FREE Full text] [doi: 10.2196/jmir.5.4.e32] [Medline: 14713660 ]

15. Norman CD, Maley O, Li X, Skinner HA. Using the internet to assist smoking prevention and cessation in schools: a randomized, controlled trial. Health Psychol 2008 Nov;27(6):799-810. [doi: 10.1037/a0013105] [Medline: 19025276]

16. Lenhart A. Teens, social media \& technology overview 2015. Washington, DC: Pew Research Center; 2015 Apr 9. URL: http://www.pewinternet.org/files/2015/04/PI_TeensandTech_Update2015_0409151.pdf [accessed 2017-01-04] [WebCite Cache ID 6nGz5ubB1]

17. Lenhart A, Ling R, Campbell S, Purcell K. Teens and mobile phones. Washington, DC: Pew Internet \& American Life Project; 2010 Apr 20. URL: http://www.pewinternet.org/files/old-media/

/Files/Reports/2010/PIP-Teens-and-Mobile-2010-with-topline.pdf [accessed 2017-01-04] [WebCite Cache ID 6nGzcxxTU]

18. Martínez-Pérez B, de la Torre-Díez I, López-Coronado M. Mobile health applications for the most prevalent conditions by the World Health Organization: review and analysis. J Med Internet Res 2013;15(6):e120 [FREE Full text] [doi: 10.2196/jmir.2600] [Medline: 23770578]

19. Glooko. Remote patient monitoring for diabetes. Mountain View, CA: Glooko, Inc; 2016. URL: https://www.glooko.com [accessed 2017-01-04] [WebCite Cache ID 6nH2XmpPI]

20. One Drop. Blue Bell, PA: Informed Data Systems Inc; 2016. URL: http://onedrop.today [accessed 2017-01-04] [WebCite Cache ID 6nH2tvFdv]

21. mySugr. Vienna, Austria: mySugr URL: https://mysugr.com [accessed 2017-01-04] [WebCite Cache ID 6nH3EXMul]

22. WellDoc. WellDoc's disruptive innovation in healthcare and mHealth uses mobile technology to transform the treatment of chronic disease. Columbia, MD: WellDoc, Inc; 2017. URL: https://www.welldoc.com/ [accessed 2017-01-04] [WebCite Cache ID 6nH3QgLvV]

23. Pham Q, Wiljer D, Cafazzo JA. Beyond the randomized controlled trial: a review of alternatives in mHealth clinical trial methods. JMIR Mhealth Uhealth 2016 Sep 09;4(3):e107 [FREE Full text] [doi: 10.2196/mhealth.5720] [Medline: 27613084]

24. Eng DS, Lee JM. The promise and peril of mobile health applications for diabetes and endocrinology. Pediatr Diabetes 2013 Jun;14(4):231-238 [FREE Full text] [doi: 10.1111/pedi.12034] [Medline: 23627878]

25. Kirwan M, Vandelanotte C, Fenning A, Duncan MJ. Diabetes self-management smartphone application for adults with type 1 diabetes: randomized controlled trial. J Med Internet Res 2013;15(11):e235 [FREE Full text] [doi: 10.2196/jmir.2588] [Medline: 24225149]

26. Quinn CC, Shardell MD, Terrin ML, Barr EA, Ballew SH, Gruber-Baldini AL. Cluster-randomized trial of a mobile phone personalized behavioral intervention for blood glucose control. Diabetes Care 2011 Sep;34(9):1934-1942 [FREE Full text] [doi: $10.2337 / \mathrm{dc11}-0366]$ [Medline: 21788632]

27. Holmen H, Torbjørnsen A, Wahl AK, Jenum AK, Småstuen MC, Arsand E, et al. A mobile health intervention for self-management and lifestyle change for persons with type 2 diabetes, part 2: one-year results from the Norwegian randomized controlled trial RENEWING HEALTH. JMIR Mhealth Uhealth 2014;2(4):e57 [FREE Full text] [doi: 10.2196/mhealth.3882] [Medline: 25499872]

28. Chomutare T, Fernandez-Luque L, Arsand E, Hartvigsen G. Features of mobile diabetes applications: review of the literature and analysis of current applications compared against evidence-based guidelines. J Med Internet Res 2011;13(3):e65 [FREE Full text] [doi: 10.2196/jmir.1874] [Medline: 21979293]

29. Arnhold M, Quade M, Kirch W. Mobile applications for diabetics: a systematic review and expert-based usability evaluation considering the special requirements of diabetes patients age 50 years or older. J Med Internet Res 2014;16(4):e104 [FREE Full text] [doi: 10.2196/jmir.2968] [Medline: 24718852]

30. El-Gayar O, Timsina P, Nawar N, Eid W. Mobile applications for diabetes self-management: status and potential. J Diabetes Sci Technol 2013;7(1):247-262 [FREE Full text] [Medline: 23439183]

31. Canadian Diabetes Association Clinical Practice Guidelines Expert Committee. Canadian Diabetes Association 2008 clinical practice guidelines for the prevention and management of diabetes in Canada. Can J Diabetes 2008;32(Suppl 1):S1-S201.

32. Cafazzo JA, Casselman M, Hamming N, Katzman DK, Palmert MR. Design of an mHealth app for the self-management of adolescent type 1 diabetes: a pilot study. J Med Internet Res 2012;14(3):e70 [FREE Full text] [doi: 10.2196/jmir.2058] [Medline: 22564332]

33. Eysenbach G, CONSORT-EHEALTH Group. CONSORT-EHEALTH: improving and standardizing evaluation reports of Web-based and mobile health interventions. J Med Internet Res 2011;13(4):e126 [FREE Full text] [doi: 10.2196/jmir.1923] [Medline: 22209829]

34. Dornhorst A, Lüddeke H, Sreenan S, Koenen C, Hansen JB, Tsur A, et al. Safety and efficacy of insulin detemir in clinical practice: 14-week follow-up data from type 1 and type 2 diabetes patients in the PREDICTIVE European cohort. Int J Clin Pract 2007 Mar;61(3):523-528. [doi: 10.1111/j.1742-1241.2007.01316.x] [Medline: 17313628]

35. Friis AM, Johnson MH, Cutfield RG, Consedine NS. Kindness matters: a randomized controlled trial of a mindful self-compassion intervention improves depression, distress, and HbA1c among patients with diabetes. Diabetes Care 2016 Nov;39(11):1963-1971. [doi: 10.2337/dc16-0416] [Medline: 27335319] 
36. Lenters-Westra E, Schindhelm RK, Bilo HJ, Groenier KH, Slingerland RJ. Differences in interpretation of haemoglobin A1c values among diabetes care professionals. Neth J Med 2014 Nov;72(9):462-466 [FREE Full text] [Medline: 25431391]

37. The Diabetes Control and Complications Trial Research Group. Hypoglycemia in the Diabetes Control and Complications Trial. Diabetes 1997 Feb;46(2):271-286. [Medline: 9000705]

38. Ingersoll GM, Marrero DG. A modified quality-of-life measure for youths: psychometric properties. Diabetes Educ 1991;17(2):114-118. [Medline: 1995281]

39. Skinner TC, Hoey H, McGee HM, Skovlund SE, Hvidøre Study Group on Childhood Diabetes. A short form of the Diabetes Quality of Life for Youth questionnaire: exploratory and confirmatory analysis in a sample of 2,077 young people with type 1 diabetes mellitus. Diabetologia 2006 Apr;49(4):621-628. [doi: 10.1007/s00125-005-0124-0] [Medline: 16525844]

40. Anderson BJ, Auslander WF, Jung KC, Miller JP, Santiago JV. Assessing family sharing of diabetes responsibilities. J Pediatr Psychol 1990 Aug;15(4):477-492. [Medline: 2258796]

41. La Greca AM, Swales T, Klemp S, Madigan S. Self care behaviors among adolescents with diabetes. 1988 Presented at: Ninth Annual Sessions of the Society of Behavioural Medicine; April 27-30, 1988; Boston, MA, USA p. A42.

42. Greco P, La Greca AM, Ireland A, Wick P, Freeman C, Agramonte R. Assessing adherence in IDDM: a comparison of two methods. Diabetes 1990;40(Suppl 1):A165.

43. Lewin AB, LaGreca AM, Geffken GR, Williams LB, Duke DC, Storch EA, et al. Validity and reliability of an adolescent and parent rating scale of type 1 diabetes adherence behaviors: the Self-Care Inventory (SCI). J Pediatr Psychol 2009 Oct;34(9):999-1007 [FREE Full text] [doi: 10.1093/jpepsy/jsp032] [Medline: 19423660]

44. Prochaska JO, DiClemente CC. Transtheoretical therapy: toward a more integrative model of change. Psychother Theory Res Pract 1982;19(3):276-288. [doi: 10.1037/h0088437]

45. Prochaska JO, Velicer WF. The transtheoretical model of health behavior change. Am J Health Promot 1997;12(1):38-48. [Medline: 10170434]

46. Bing D, He X. Linear mixed models in clinical trials using PROC MIXED. 2010 Presented at: PharmaSUG2010; May 23-26, 2010; Orlando, FL, USA p. SP07 URL: http://www.lexjansen.com/pharmasug/2010/SP/SP07.pdf

47. Arnau J, Bendayan R, Blanca MJ, Bono R. The effect of skewness and kurtosis on the robustness of linear mixed models. Behav Res Methods 2013 Sep;45(3):873-879. [doi: 10.3758/s13428-012-0306-x] [Medline: 23299397]

48. Long term mobile game success: beyond awareness and adoption. New York, NY: The Nielsen Company; 2016 Oct 18. URL: http://www.nielsen.com/us/en/insights/news/2016/long-term-mobile-game-success-beyond-awareness-and-adoption.

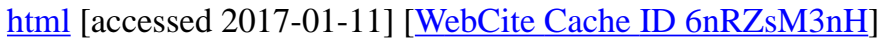

49. Bot BM, Suver C, Neto EC, Kellen M, Klein A, Bare C, et al. The mPower study, Parkinson disease mobile data collected using ResearchKit. Sci Data 2016 Mar 03;3:160011 [FREE Full text] [doi: 10.1038/sdata.2016.11] [Medline: 26938265]

50. Deacon AJ, Edirippulige S. Using mobile technology to motivate adolescents with type 1 diabetes mellitus: a systematic review of recent literature. J Telemed Telecare 2015 Dec;21(8):431-438. [doi: 10.1177/1357633X15605223] [Medline: 26377124]

51. Collins LM, Murphy SA, Strecher V. The multiphase optimization strategy (MOST) and the sequential multiple assignment randomized trial (SMART): new methods for more potent eHealth interventions. Am J Prev Med 2007 May;32(5 Suppl):S112-S118 [FREE Full text] [doi: 10.1016/j.amepre.2007.01.022] [Medline: 17466815]

\author{
Abbreviations \\ ANOVA: analysis of variance \\ DFRQ: Diabetes Family Responsibility Questionnaire \\ DQOLY: Diabetes Quality of Life for Youth \\ HbA1c: hemoglobin A1c \\ RCT: randomized controlled trial \\ SMART: Sequential Multiple Assignment Randomized Trial \\ SMBG: self-monitoring of blood glucose
}

Edited by G Eysenbach; submitted 17.01.17; peer-reviewed by H Holmen, S de Vries, A Cross; comments to author 02.02.17; revised
version received 16.03.17; accepted 06.05.17; published 19.06.17
Please cite as:
Goyal S, Nunn CA, Rotondi M, Couperthwaite AB, Reiser S, Simone A, Katzman DK, Cafazzo JA, Palmert MR
A Mobile App for the Self-Management of Type 1 Diabetes Among Adolescents: A Randomized Controlled Trial
JMIR Mhealth Uhealth 2017;5(6):e82
URL: $\underline{\text { http://mhealth.jmir.org/2017/6/e82/ }}$
doi: $\underline{10.2196 / \text { mhealth. } 7336}$
PMID: $\underline{28630037}$ 
(CShivani Goyal, Caitlin A Nunn, Michael Rotondi, Amy B Couperthwaite, Sally Reiser, Angelo Simone, Debra K Katzman, Joseph A Cafazzo, Mark R Palmert. Originally published in JMIR Mhealth and Uhealth (http://mhealth.jmir.org), 19.06.2017. This is an open-access article distributed under the terms of the Creative Commons Attribution License (https://creativecommons.org/licenses/by/4.0/), which permits unrestricted use, distribution, and reproduction in any medium, provided the original work, first published in JMIR mhealth and uhealth, is properly cited. The complete bibliographic information, a link to the original publication on http://mhealth.jmir.org/, as well as this copyright and license information must be included. 